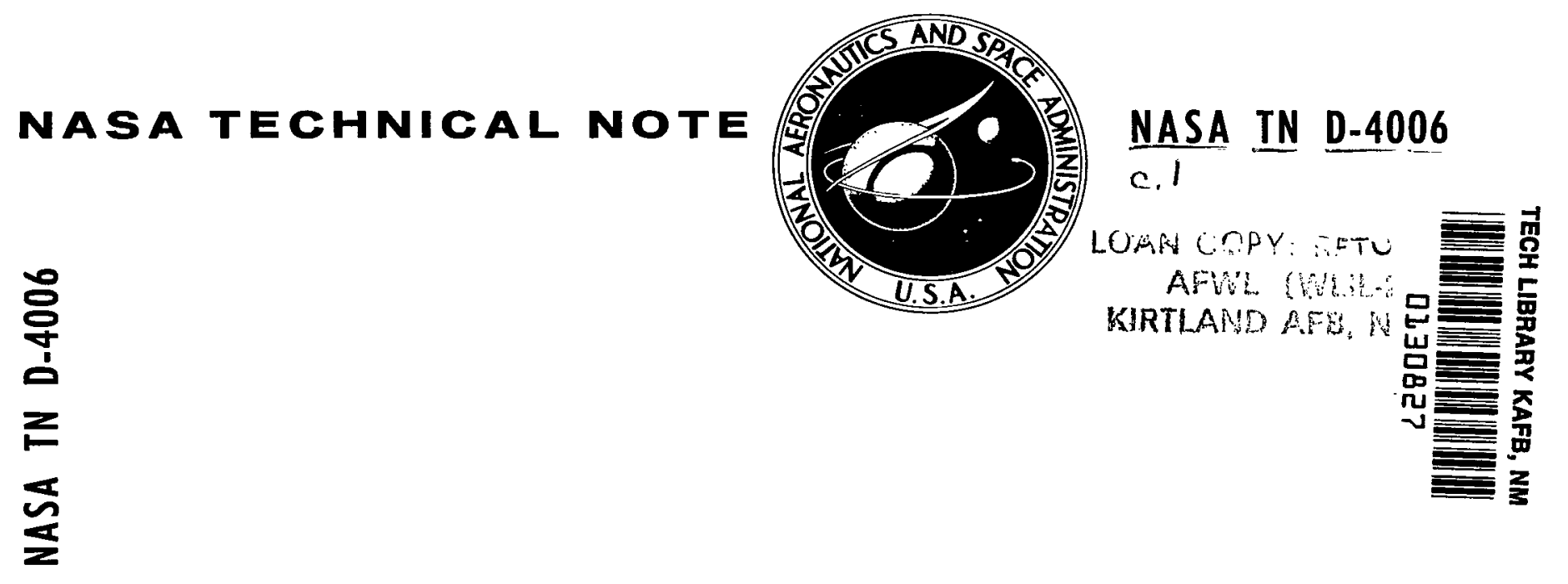

\title{
THE ATTAINMENT OF CLEAN VACUUM WITH A ONE-WATT REFRIGERATOR
}

by James E. A. John and William F. Hardgrove Goddard Space Flight Center Greenbelt, $M d$.

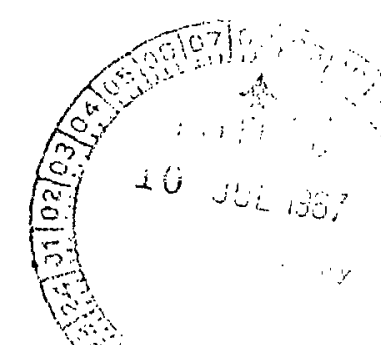

national aeronautics and SPACe administration - Washington, D. C. • JULY 1967 
THE ATTAINMENT OF CLEAN VACUUM

WITH A ONE-WATT REFRIGERATOR

By James E. A. John and William F. Hardgrove

Goddard Space Flight Center

Greenbelt, Md. 


\begin{abstract}
A 1-watt refrigerator was used to maintain a 2-squarefoot cryopanel at temperatures below $20^{\circ} \mathrm{K}$ in a 600 -liter vacuum chamber. With the chamber roughed to 50 microns with a mechanical pump, ultimate pressures in the $10^{-8}$ tor $r$ range were consistently obtained in an unbaked chamber with the cryopanel in operation. To reduce the heat load in the refrigerator, the cryopanel was surrounded with liquid-nitrogen-cooled chevron baffles. Pumping speeds of the panel for air, argon, and nitrogen of the order of 5000 liters per second were measured over the range $10^{-4}$ to $10^{-6}$ torr. The composition of the residual gases in the chamber during several operating conditions is reported.

Results of the experimentation indicate that a relatively low-capacity refrigerator can be used to produce and maintain high vacuum in a test chamber of reasonable volume. The use of cryogenic pumping serves also to reduce to a minimum the contamination introduced into the test volume by the pumping system.
\end{abstract}


CONTENTS

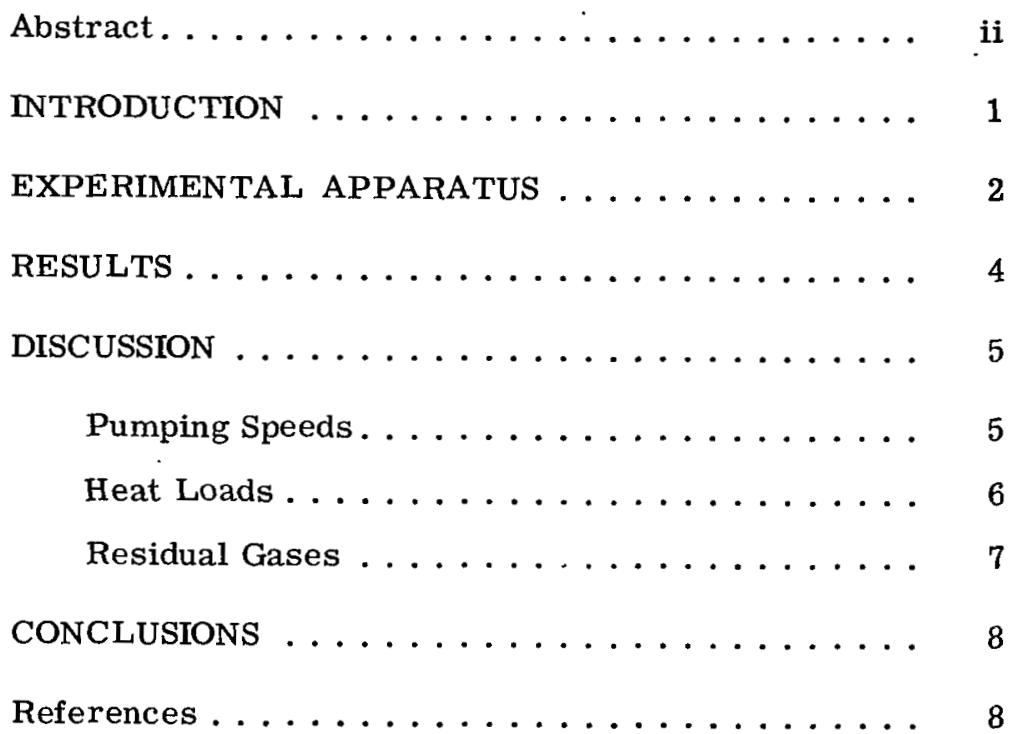




\title{
THE ATTAINMENT OF CLEAN VACUUM WITH A ONE-WATT REFRIGERATOR
}

\author{
by \\ James E. A. John and William F. Hardgrove \\ Goddard Space Flight Center
}

\section{INTRODUCTION}

The increasing complexity, precision, and contamination-susceptibility of spacecraft experiments necessitate "clean-room" conditions throughout the entire testing period. Therefore, there is a need to reduce the possibility of inadvertent contamination of instrumentation and surfaces exposed to environmental tests in a space simulator. A primary area for contamination control is the vacuum system of the space simulator. Cryogenic systems eliminate oil contamination as well as problems that may be associated with electronic and magnetic effects of ion pumps and titanium sublimators.

At the present time, there is a need in many areas of vacuum technology, such as thin-film research and space simulation, for the capability of evacuating a test volume to pressures below $10^{-5}$ torr without the introduction of contaminants into the test volume. Although the contamination produced from the backstreaming of an oil diffusion pump or ion pump can be reduced by careful operating procedures and suitable trapping, the only inherently clean pumping mechanism at present is cryogenic pumping. This process involves the removal of molecules in the test volume by condensation on cryogenically cooled surfaces. Cryopumping is being used in many vacuum facilities at the present time, but almost exclusively as an auxiliary pumping mechanism used with the oil diffusion pump or ion pump. Therefore, the possibility of contamination still exists in such systems.

This report presents the results of a series of experiments designed to demonstrate the operating characteristics of a cryogenic vacuum pumping system over the pressure range $10^{-2}$ to $10^{-8}$ torr. A 1 -watt $20^{\circ} \mathrm{K}$ refrigerator was used to provide the low-temperature cryopumping surfaces for a test chamber, 3 feet in height and 3 feet in diameter, rough-pumped to approximately 50 microns with a rotary mechanical pump. Of primary interest were the cooldown and pumpdown time of the cryopump; the residual gas composition after cooldown; the pumping speed for air, nitrogen, and argon; and the ultimate pressure obtainable for the system with no test item in the test volume. It is believed that the information obtained with the use of a relatively low capacity refrigeration unit demonstrates the feasibility of an all-cryogenic pumping system. 


\section{EXPERIMENTAL APPARATUS}

The refrigeration engine used to cool the cryosurface was an ADL Model 600 Creacher Helium Refrigerator. Basically, this engine consists of a cylinder fitted with two displacers which divide the cylinder volume into three zones. A hot zone is maintained at room temperature, an intermediate zone at liquid-nitrogen temperature, and a cold zone at $20^{\circ} \mathrm{K}$ and below.

A heat engine operating between room temperature and liquid nitrogen zones is used to drive a heat pump, or refrigerator, to cool the low-temperature zone. The cold zone is divided into two stages in order to provide a more efficient system. Details of the engine operation are provided by Chellis and Hogan (Reference 1).

The cold end of the refrigerator was allowed to protrude into the test volume through the vacuum-chamber baseplate. Four gold-plated copper panels were attached to the cold end by means of a copper flange. These panels provided a condensing surface of 2.0 square feet. Surrounding these cryosurfaces was a blackened-copper, liquid-nitrogen-cooled, chevron radiation shield (see Figure 1).

During operation, cold-zone temperatures were measured with gold cobalt thermocouples attached to the two stages of the cold zone. Liquid-nitrogen reference junctions were used for these thermocouples to minimize the generation of emf's from temperature gradients along the thermocouple wires. Also, a hydrogen-vapor pressure gauge, attached to the cryopanel, was used to monitor the cold zone temperature.

The vacuum chamber was a cylinder, 3 feet in diameter by 3 feet in height, with double elastomer O-ring seals at baseplate and dome. Feedthrough ports were available in the baseplate for the inclusion of the desired vacuum instrumentation. The chamber could not be baked because of several soft-soldered joints on the refrigerator and Micarta displacers in the engine.

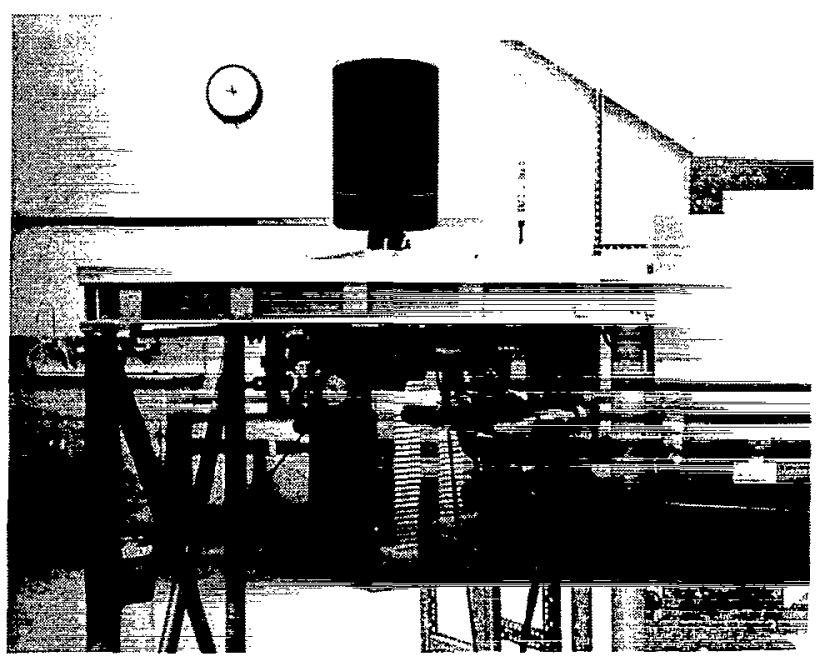

Figure 1-Cryopump installation.

A General Electric Trigger Vacuum Gauge, with magnet encapsulated, was supported inside the test volume to measure the total pressure. A CEC 613 Residual Gas Analyzer (connected to the test volume through a 2-inchdiameter stainless steel tube 28 inches long) was employed to determine the partial pressures of gases present in the' chamber. Relative locations of this vacuum instrumentation are shown in Figure 2.

In order to measure the pumping speed of the cryopump for various gases, a controlled leak of the gas under consideration was admitted to the test volume. The gas metering system used is shown in Figure 3. The storage volume 
$\left(2024 \mathrm{~cm}^{3}\right)$ was first filled with the test gas to a pressure of about one atmosphere, and the remainder of the system evacuated. With the chamber valve closed, the variable-leak valve was opened the specified number of turns, and the resultant rate of pressure rise in the calibrated volume $\left(89.3 \mathrm{~cm}^{3}\right)$ measured with a mercury manometer. The resultant gas flow is expressed as

$$
Q=v_{2} \frac{d P_{2}}{d t}
$$

where

$v_{2}=$ the volume of the metering system downstream of the valve

$\frac{\mathrm{dP}_{2}}{\mathrm{dt}}=$ the rate of pressure rise in this volume.

This gas flow was then admitted to the test chamber. In this system, flows over the range $10^{-1}$ to $10^{-5}$ torr-liters per second could be measured accurately.

During operation, the test chamber was first evacuated to a pressure of approximately 50 microns with a mechanical pump. This pump was then valved off and the refrigerator put into operation. Pumpdown curves, showing the trigger gauge pressure versus time, were obtained during cooldown. After the ultimate pressure was attained, the spectrometer was used to analyze the residual gases. Measurements were made to ascertain the pumping speed of the cryopump for air, nitrogen, and argon. Controlled leaks of each gas were admitted to the chamber, with the speed calculated from

$$
\mathbf{S}=\frac{\mathbf{Q}}{\mathbf{P}-\mathbf{P}_{\mathrm{e}}}
$$

where

$P=$ steady-state chamber pressure during admission of the known leak rate

$P_{e}=$ steady-state chamber pressure prior to inleak.
MASS

SPECTROMETER

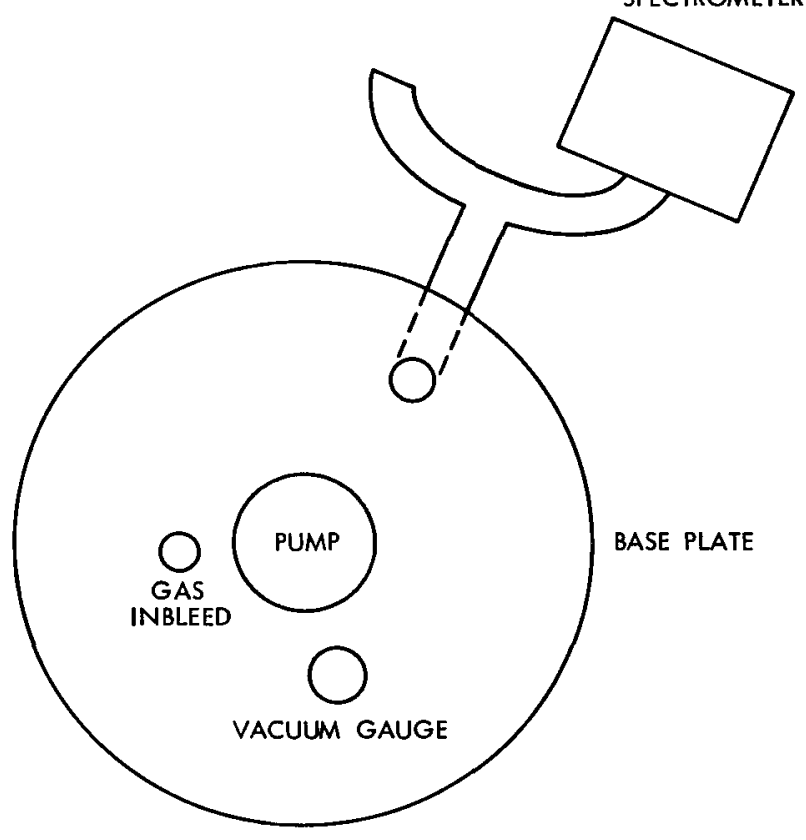

Figure 2-Location of instrumentation.
Figure 3-Gas metering system.

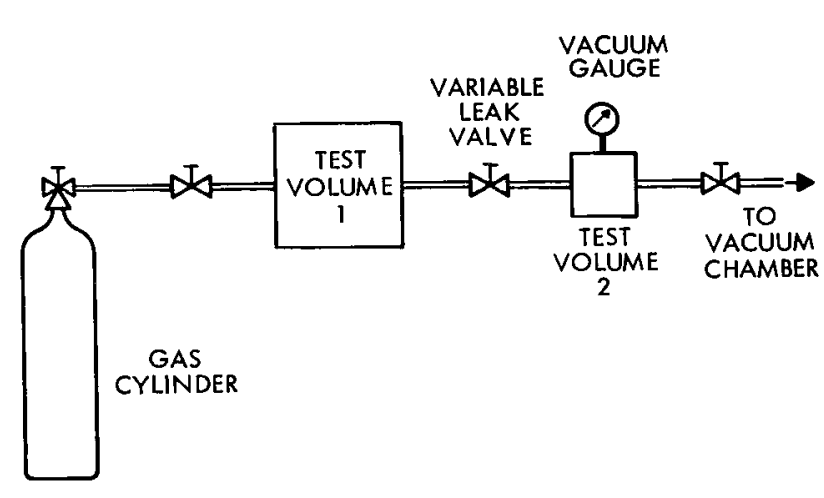


The pressures $P$ and $P_{e}$ were measured with the mass spectrometer and the trigger gauge.

\section{RESULTS}

A typical pumpdown curve is shown in Figure 4, which depicts the second- and final-stage cold-zone temperatures and chamber pressure as a function of time measured from the startup of the refrigerator. Ultimate pressures on the $10^{-8}$ torr scale were obtained repeatedly after 3 to 4 hours operation.

Results of the pumping speed measurements for argon, air, and nitrogen are shown in Figure 5 and Table 1. All results quoted were calculated from measurements made with the trigger gauge.

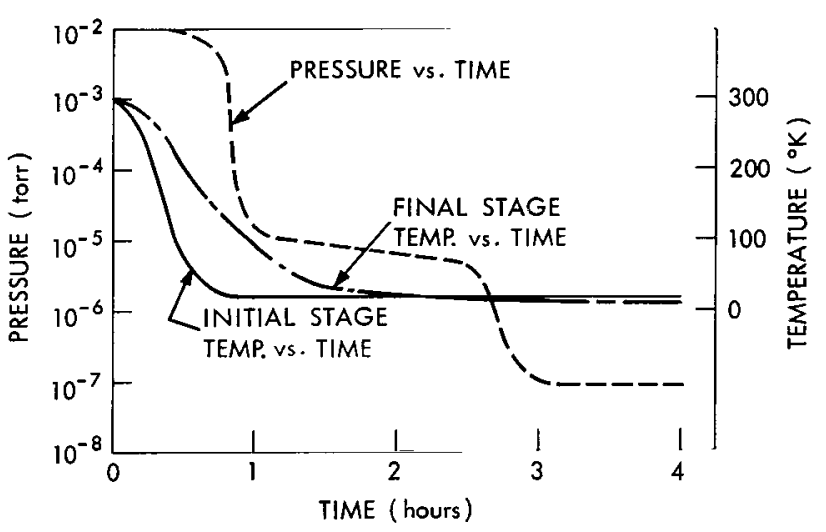

Figure 4-Pump-down curves.

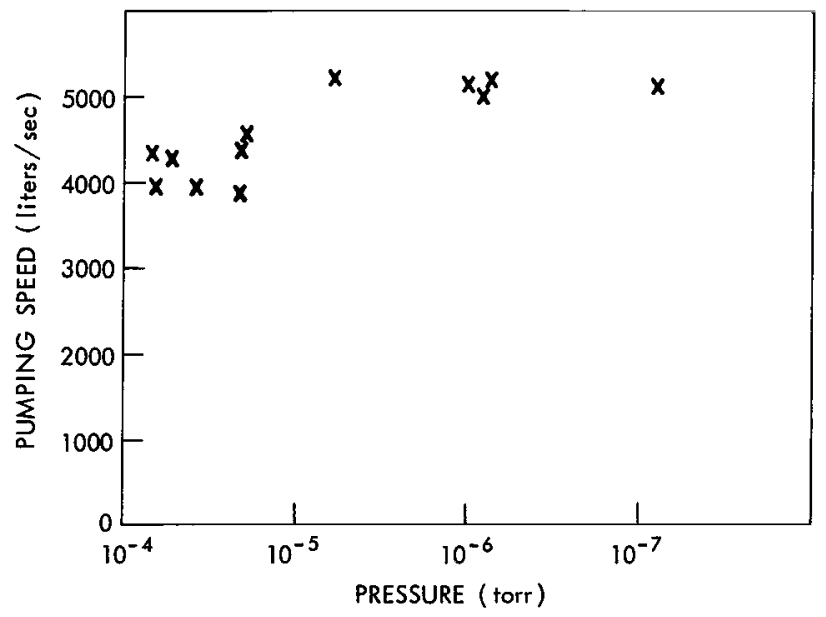

Figure 5-Pumping speed for air.

Table 1

Pumping Speed Measurements.

\begin{tabular}{c}
$\mathrm{Q}$ \\
(torr-liter/second) \\
\hline $4.95 \times 10^{-3}$ \\
$5.95 \times 10^{-3}$ \\
$1.11 \times 10^{-2}$
\end{tabular}

$\mathrm{P}$
(torr)
$9.0 \times 10^{-7}$
$1.2 \times 10^{-6}$
$2.1 \times 10^{-6}$
$1 \times 10^{-3}$
$9 \times 10^{-3}$
$2.4 \times 10^{-3}$

Test Gas: Nitrogen

\begin{tabular}{|c|c}
$\mathrm{P}_{\mathrm{e}}$ \\
(torr) & $\mathrm{S}$ \\
$3.8 \times 10^{-8}$ & 5700 \\
$8.6 \times 10^{-8}$ & 5400 \\
$1 \times 10^{-7}$ & 5550
\end{tabular}

Test Gas: Argon

\begin{tabular}{|l|l|}
$2.4 \times 10^{-8}$ & 5660 \\
$7.0 \times 10^{-9}$ & 5300 \\
$5.0 \times 10^{-9}$ & 5700
\end{tabular}

Cryopanel Temperature ( $\left.{ }^{\circ} \mathrm{K}\right)$ 15 15 16

15


Pumping speeds calculated from the spectrometer partial pressures were consistently 20 percent higher than speeds calculated from the gauge data. The dependence of a pumping speed measurement on gauge location is discussed by Stickney and Dayton (References 2 and 3). For example, since the gauge was located closer to the inleak source than was the spectrometer, the gauge would be in a region of greater molecular flux density than the spectrometer and would thus indicate a greater pressure and lower speed. Furthermore, the location of the pumping surface with respect to gauge, spectrometer, and inleak source would contribute to the difference in pumping-speed measurement. Considerably more investigation of pumping measurements is required, taking into account gauge location, pump, and inleak source location. The results quoted in this report are understood to be somewhat apparatus-dependent.

Each of the test gases was allowed to bleed into the test space at a controlled rate of approximately $10^{-3}$ torr-liters/second for over 24 hours. Over this period, no change in speed was noted.

Residual-gas analyses of the test volume after the ultimate pressure was attained revealed that the majority of the gases present consisted of nitrogen, helium, hydrogen, and water vapor. A typical result of a spectrometer scan taken with an empty chamber is shown in Table 2. Also shown is a scan taken after a 24-hour air inleak of $5 \times 10^{-3}$ torrliters/second. Both scans were taken with the leak valve closed.
Table 2

Residual Gas Data.

\begin{tabular}{|l|c|c|} 
Gas & $\begin{array}{c}\text { Partial pressure } \\
\text { before air inleak } \\
\text { (torr) }\end{array}$ & $\begin{array}{c}\text { Partial pressure } \\
\text { after air inleak } \\
\text { (torr) }\end{array}$ \\
$\mathrm{H}_{2} \mathrm{O}$ & $6.7 \times 10^{-8}$ & $1.7 \times 10^{-8}$ \\
$\mathrm{~N}_{2}$ & $2.5 \times 10^{-8}$ & $9 \times 10^{-9}$ \\
$\mathrm{He}$ & $1.6 \times 10^{-8}$ & $1 \times 10^{-7}$ \\
$\mathrm{H}_{2}$ & $7 \times 10^{-9}$ & $3 \times 10^{-9}$ \\
\hline
\end{tabular}

\section{DISCUSSION}

\section{Pumping Speeds}

The volume flow of gas molecules incident on a unit surface in the free molecular flow regime is given by kinetic theory:

$$
\dot{\mathrm{V}}=\sqrt{\frac{\mathrm{RT}}{2 \pi \mathrm{M}}},
$$

where $\mathrm{T}$ is the gas temperature and $\mathrm{M}$ the gas molecular weight.

All the incident molecules that strike a cryogenic surface do not stick to the surface, however, so that it is appropriate to define a net sticking coefficient $f$ such that

$$
\mathbf{S}=\dot{\mathrm{f}} \dot{\mathrm{V}},
$$


where $f$ depends on the ratio of the vapor pressure of the gas at the cryosurface temperature to the partial pressure of the gas in the chamber, the kinetic energy of the incident gas molecules, etc. In the case under study, the cryosurface was baffled with liquid-nitrogen chevrons to reduce the radiant heat load on the cryosurface. The effect of the baffle is to reduce the net pumping speed of the array. The transmission coefficient of the $45^{\circ}$ chevron baffles used was found to be 0.25 (Reference 4). Therefore, if all the molecules passing through the baffles were to stick to the cryosurface, the pumping speed, for a 2.0-square foot surface, would be

$$
\mathrm{S}_{\max }=\frac{1}{4} \times 2 \sqrt{\frac{\mathrm{RT}}{2 \pi \mathrm{M}}}
$$

for nitrogen at $300^{\circ} \mathrm{K}, \mathrm{S}_{\max }=5580$ liters $/$ second; for argon, $\mathrm{S}_{\max }=4660$ liters $/$ second; and, for air, $\mathrm{S}_{\max }=5470$ liters $/$ second.

The nitrogen and air pumping-speed data thus indicate sticking coefficients on the $14-15^{\circ} \mathrm{K}$ cryosurface approaching one. The data presented for argon are suspect, since the gauge sensitivity for argon was unknown.

The data for air show a dropoff of pumping speeds at the higher pressures $\left(10^{-4}\right.$ torr $)$. At these pressures, with rates of inleak of up to $5 \times 10^{-1}$ torr-liters per second, the load on the system due to the heat of condensation and due to convective heat transfer is an appreciable fraction of the refrigeration capacity ( 1 watt). The cryosurface temperature during these runs was observed to rise by as much as $3^{\circ} \mathrm{K}$.

\section{Heat Loads}

For a 1-watt refrigerator to be able to produce and maintain cryosurface temperatures below $20^{\circ} \mathrm{K}$, it is necessary to reduce heat loads on the cryosurface to a minimum. With steady-state heat loads due to radiation alone, the problem can be alleviated by surrounding the cryosurface with blackened liquid-nitrogen-cooled chevrons. Thus

$$
\frac{\dot{\mathrm{q}}_{\mathrm{r}}}{\mathrm{A}_{1}}=\frac{\sigma\left(\mathrm{T}_{2}^{4}-\mathrm{T}_{1}^{4}\right)}{\frac{1-\varepsilon_{1}}{\varepsilon_{1}}+\frac{\left(1-\varepsilon_{2}\right) \mathrm{A}_{1}}{\varepsilon_{2} \mathrm{~A}_{2}}+1},
$$

where $\dot{\mathrm{q}}_{\mathrm{r}}$ is the radiation heat load, $\sigma$ the Stefan-Boltzmann constant, and $\varepsilon$ the surface emissivity. The subscript 1 refers to the cryosurface, and subscript 2 to the surrounding chevron surfaces. For $\varepsilon_{1}=0.1$ and $\varepsilon_{2}=1$ :

$$
\begin{aligned}
\frac{\dot{\mathrm{q}}_{\mathrm{r}}}{\mathrm{A}_{1}} & =\sigma\left(\mathrm{T}_{2}^{4}-\mathrm{T}_{1}^{4}\right) \varepsilon_{1} \\
& =\left(5.67 \times 10^{-8}\right)\left(77^{4}-20^{4}\right)(0.1) \\
& =0.199 \text { watts } / \mathrm{m}^{2} .
\end{aligned}
$$


For the area of the cryosurfaces used, this represents a heat load of 0.04 watts, small in comparison to the refrigeration capacity of 1 watt. The condensation heat load is equal to

$$
\dot{\mathrm{q}}_{\mathrm{c}}=\dot{\mathrm{m}} \Delta \mathrm{H},
$$

where $\dot{m}$ is the mass flux condensed per unit time and $\Delta H$ the specific enthalpy difference between the vapor and condensed phases of the test gas. For an inbleed of $10^{-1}$ torr-liters/second, $\dot{\mathrm{q}}_{c}$ is much less than 0.1 watt.

With the minimal heat loads evaluated above, the 1 -watt refrigerator was consistently able to maintain cryopanel temperatures of 14 to $15^{\circ} \mathrm{K}$.

\section{Residual Gases}

At cryosurface temperatures of $20^{\circ} \mathrm{K}$ and below, the gases possessing appreciable vapor pressures are hydrogen, helium, and neon. Further, with an unbaked chamber, surface gases are continually evolving from the chamber walls and may constitute an appreciable fraction of the residual gases present. Thus, for example, whereas large surface areas cooled to liquid nitrogen temperatures were available for pumping water vapor, the rate of evolution of water vapor from the walls was such that this was the principal gas in the chamber at steady state. Hydrogen, although not present to an appreciable extent in air, has been shown to be a constituent of the gases evolved from stainless steel walls under vacuum (Reference 5). Thus, the chief gases present in the cryogenically pumped chamber were helium and nitrogen from air initially present in the chamber and leaked into the chamber, and hydrogen and water vapor from outgassing.

It is interesting to observe from Table 2 that the hydrogen and water vapor peaks decreased after a continuous air inbleed. With no provision for condensing hydrogen at the chamber pressure involved, the decrease in hydrogen partial pressure was probably due to cryotrapping, the capture of the hydrogen molecules under other condensable constituents. Decrease in the rate of water vapor evolution from metallic surfaces after long-term vacuum pumping is reported in Reference 6 and was demonstrated here by the decrease of water-vapor partial pressure.

The increase of helium partial pressure after long-term air inbleed points out a difficulty of operating an all-cryogenic system. Air is composed of 5 parts per million of helium, so that if air were to inleak at the rate of $10^{-3}$ torr-liters/second the helium inbleed would amount to $5 \times 10^{-9}$ torr-liters/second. The chamber used was 600 liters in volume, so that the partial pressure of helium would increase at a rate $8 \times 10^{-12}$ torr/second. After 24 hours, this would amount to an increase in the helium partial pressure of $7 \times 10^{-7}$ torr. For long-term operation in a system with an appreciable air leak, auxiliary means must be provided to handle the noncondensable gases. 


\section{CONCLUSIONS}

A relatively low capacity refrigerator, providing cryosurface temperatures down to $15^{\circ} \mathrm{K}$, can be used to evacuate a chamber of 600 -liter volume over the range $10^{-2}$ torr to $10^{-8}$ torr. Heat loads on the refrigeration unit can be reduced well below 1 watt by suitable baffling of the cryosurface. The baffled pumping speed of the cryopump for air was found to be approximately 5000 liters per second over the range $10^{-5}$ to $10^{-7}$ torr. Principal components of the residual gases in the cryopumped chamber were hydrogen, helium, water vapor, and nitrogen.

Goddard Space Flight Center

National Aeronautics and Space Administration

Greenbelt, Maryland, January 10, 1967

124-09-05-08-51

\section{REFERENCES}

1. Chellis, F. F., and Hogan, W. H., "A Liquid-Nitrogen-Operated Refrigerator for Temperatures Below $77^{\circ} \mathrm{K}$," Proceedings of Cryogenic Engineering Conference, Boulder, Colorado: Plenum Press, August 1963.

2. Stickney, W. W., and Dayton, B. B., "The Measurement of the Speed of Cryopumps," Trans. Amer. Vacuum Soc., 1963.

3. Dayton, B. B., "The Measured Speed of an 'Ideal Pump'," Vacuum, 15(2):53-57, February 1965.

4. Levenson, L. L., "Optimization of Molecular Flow Conductance," Univ. of Calif. Radiation Lab. Report UCRL-6014, August 1960.

5. Calder, R., and Lewin, G., "Reduction of Stainless Steel Outgassing in Ultra-high Vacuum," presented at the Thirteenth National Vacuum Symposium, American Vacuum Society, San Francisco, October 1966.

6. Barrington, A. E., "High Vacuum Engineering," p. 190, Englewood Cliffs, N. J.: PrenticeHall, 1963. 
"The aeronautical and space activities of the United States shall be conducted so as to contribute . . . to the expansion of buman knowledge of phenomena in the atmosphere and space. The Administration sball provide for the widest practicable and appropriate dissemination of information concerning its activities and the results thereof."

- National Aeronautics and Spacb ACt of 1958

\section{NASA SCIENTIFIC AND TECHNICAL PUBLICATIONS}

TECHNICAL REPORTS: Scientific and technical information considered important, complete, and a lasting contribution to existing knowledge.

TECHNICAL NOTES: Information less broad in scope but nevertheless of importance as a contribution to existing knowledge.

TECHNICAL MEMORANDUMS: Information receiving limited distribution because of preliminary data, security classification, or other reasons.

CONTRACTOR REPORTS: Scientific and technical information generated under a NASA contract or grant and considered an important contribution to existing knowledge.

TECHNICAL TRANSLATIONS: Information published in a foreign language considered to merit NASA distribution in English.

SPECIAL PUBLICATIONS: Information derived from or of value to NASA activities. Publications include conference proceedings, monographs, data compilations, handbooks, sourcebooks, and special bibliographies.

TECHNOLOGY UTILIZATION PUBLICATIONS: Information on technology used by NASA that may be of particular interest in commercial and other non-aerospace applications. Publications include Tech Briefs, Technology Utilization Reports and Notes, and Technology Surveys.

Details on the availability of these publications may be obtained from:

SCIENTIFIC AND TECHNICAL INFORMATION DIVISION

NATIONAL AERONAUTICS AND SPACE ADMINISTRATION

Washingion, D.C. 20546 